\title{
Jeanne Goldin, Construction du personnage autobiographique
}

\section{Morena Petrich}

\section{Q OpenEdition \\ 1 Journals}

\section{Edizione digitale}

URL: http://journals.openedition.org/studifrancesi/27817

DOI: 10.4000/studifrancesi.27817

ISSN: 2421-5856

\section{Editore}

Rosenberg \& Sellier

\section{Edizione cartacea}

Data di pubblicazione: 31 décembre 2006

Paginazione: 623

ISSN: 0039-2944

\section{Notizia bibliografica digitale}

Morena Petrich, « Jeanne Goldin, Construction du personnage autobiographique », Studi Francesi [Online], 150 (L | III) | 2006, online dal 30 novembre 2015, consultato il 08 novembre 2020. URL : http:// journals.openedition.org/studifrancesi/27817 ; DOI : https://doi.org/10.4000/studifrancesi.27817

Questo documento è stato generato automaticamente il 8 novembre 2020.

\section{(c) (i) (9)}

Studi Francesi è distribuita con Licenza Creative Commons Attribuzione - Non commerciale - Non opere derivate 4.0 Internazionale. 


\section{Jeanne Goldin, Construction $d u$ personnage autobiographique}

Morena Petrich 


\section{NOTIZIA}

JEANNE GOLDIN, Construction du personnage autobiographique, George Sand Studies, Vol. 24, 2005, pp. 59-73.

Intraprendendo, a metà della sua esistenza terrena, la redazione della sua autobiografia, George Sand incorse in una sfida densa di pericoli che le attirò molte critiche, sia per quanto vi raccontò che per quanto vi tacque. L'A. prende le mosse dalla lettura di Sartre, elaborata dallo studioso e scrittore Serge Doubrovsky, per sondare il rapporto e le implicazioni tra autobiografia e creazione letteraria in Histoire de ma vie, in cui Sand fece sapientemente ricorso a tutte le armi e gli espedienti del mestiere che mirabilmente padroneggiava, autrice oltremodo prolifica e straordinariamente produttiva, entrando ed uscendo incessantemente da sfera conscia e inconscia. L'obiettivo primario della scrittrice fu presto dichiarato e già nell'introduzione - citata nell'articolo da Jeanne Goldin - Sand dichiarò propositi fermamente assunti nella trascrizione dei suoi ricordi: "Charité envers les autres. Dignité envers soi-même. Sincérité envers Dieu. Telle est l'épitaphe du livre que j'entreprends". E proprio questi propositi offuscarono in parte la sincera pittura dei fatti e delle persone, secondo ciò che in una lettera, a proposito di Elle et lui al suo editore Buloz nel 1859, intese come "perdonare" piuttosto che dissimulare o nascondere. Ciò che Sand non celò mai fu la sua passione e il riconoscimento dell'imprescindibile valore esistenziale della scrittura. E fu proprio su questo primario fattore identitario che Sand (come d'altronde Sartre, che l'A. ci propone in un pregnante parallelismo) costruì ed incontrò il senso della (sua) vita: vocazione e salvezza si fondano e si rinsaldano, risvolti di un'unica via all'esistenza. 